\title{
Audit of a British Centre for spinal injury
}

\author{
Tun S Aung and Wagih S El Masry \\ The Midlands Centre for Spinal Injuries, The Robert Jones \& Agnes Hunt Orthopaedic and District Hospital, \\ Oswestry, UK
}

\begin{abstract}
The aim of this study was to determine the benefits of patients admitted early to the specialist spinal injuries centre. The results show a significant reduction in the incidence of pressure sores in the early admitted patients and demonstrate the lowered incidence of both preventable and non preventable complications, as well as reduction of hospitalisation time.
\end{abstract}

Keywords: spinal cord injury; early, delayed and late admissions; medical complications; length of stay; audit

\section{Introduction}

Spinal Injuries Centres are now well established in the United Kingdom and are equipped to resuscitate, manage and rehabilitate patients with traumatic and non traumatic spinal paralysis as well as provide a life long follow up and management for these patients. ${ }^{1}$ One of the major activities of Spinal Injuries Centres is the prevention of complications related to the multisystem impairment caused by the spinal paralysis both in the short and long term. Delays in the transfer of spinal injured patients to the specialist care may have an adverse effect on the outcome of the patient and the development of complications eg pressure sores, bladder problems etc, as well as result in prolonged hospitalisation times. ${ }^{2-6}$

This study has been designed to examine the relationship between the delay in admission to the Centre and the development of complications during the first post traumatic period of hospitalisation. The study is limited by the lack of accurate pre-admission information and the lack of information on morbidity and mortality of patients not referred to the Centre.

\section{Methods}

The Midlands Centre for Spinal Injuries has 45 beds to serve the Midlands, North Wales, Mid Wales and South Mersey (about 7.5 million population). At any one time about 30 beds are occupied by newly paralysed patients and the other 15 for re-admission and life long review from a total of about 1500 patients. A retrospective study was carried out on the case notes of all new admissions to the Midlands Centre for Spinal Injuries between January 1985 and

Correspondence: WS El Masry
December 1988. The follow up period ranged between 2 and 5 years. A total of 322 first admissions was recorded during this 4 year period. The patients' characteristics are shown in Table 1.

About $18 \%$ of the patients had paralysis of non traumatic origin. There were 219 patients with spinal paralysis in the trauma group, of which 173 were male, with an average age of 35.5 years and 46 females, with an average age of 44.2 years. Forty two patients with intact neurology and four patients with conversion reaction were excluded.

An analysis of the cause of injury revealed that road traffic accidents account for about $50 \%$ of these injuries (Table 2). Fifty three per cent of the patients had locomotor as well as a multi-system impairment from the neck downwards (Table 3). The incidence of double fractures of the spinal axis was previously documented by Gupta and El Masry ${ }^{7}$ in 1989 and in this series it was also found to be $9 \%$. About $30 \%$ of the patients had associated injuries: 25 patients $(11.4 \%)$ had haemo pneumothorax; 32 patients $(14.6 \%)$ had skeletal fractures (limbs, ribs, sternum, clavicle, pelvis, skull); four patients $(1.8 \%)$ had traumatic brain injury; one patient $(0.45 \%)$ had a brachial plexus injury; one patient $(0.45 \%)$ had a ruptured aorta. In spite of these associated injuries the clinical outcome was not affected adversely as there was no neurological deterioration on the Frankel scale.

The patients were divided into three groups.

\section{Group 1}

Early admission when the patients were admitted within 1 week of injury.

\section{Group 2}

Delayed admission when patients were admitted over 1 week but within 2 months from injury. Usually the 
Table 1 Patients' characteristics

\begin{tabular}{lr}
\hline Traumatic Spinal Injury & \\
\hline Cord injury with paralysis & 219 \\
Bony injury with intact neurology & 42 (Excluded) \\
Conversion reaction & 4 (Excluded) \\
Non Traumatic Spinal Lesion & 57 (Excluded) \\
\hline
\end{tabular}

Table 2 Causes of injury

Road traffic accident 110

Falls; Domestic and industrial accidents $\quad 93$

Sporting injuries

Table 3 Level of bony injury

\begin{tabular}{lr}
\hline Cervical & 116 patients $(53 \%)$ \\
Thoracic & 73 patients $(33.3 \%)$ \\
Lumbar & 30 patients $(13.7 \%)$ \\
\hline
\end{tabular}

Of these, 20 patients $(9 \%)$ had double fractures

delays were due to difficulties in transfers or unavailability of beds on the Midlands Centre for Spinal Injuries.

\section{Group 3}

Late admissions when patients were admitted over 2 months from injury (Table 4).

Over $70 \%$ of patients were admitted within 1 week of injury, $20 \%$ within 2 months of injury and only $8.7 \%$ of patients were admitted after 2 months. Late admissions were usually due to late referrals.

The Midlands Centre for Spinal Injuries has a multi-disciplinary team of Doctors, Nurses, Physiotherapists, Occupational Therapists, a part-time Psychologist and a Social Worker to deal with the multi-system impairment as well as the psycho-social support and psycho-social engineering required for the resettlement in the community.

An 'injury to grave' service as described by Guttmann and others ${ }^{14}$ is offered to all patients and accepted by the majority.

The Centre has a $24 \mathrm{~h}$ telephone consultation service to advise on management prior to acute admission, following discharge and if necessary, prior to re-admission for treatment or further rehabilitation. A team of three hospital based Liaison Officers commence the resettlement process from a very early stage. Hence the majority of patients were discharged to their own homes in the community. Only $6 \%$ of the patients were discharged to other hospitals and nursing homes (Table 5).

\section{Results}

Table 4 shows the median values for average total hospitalisation from accident to discharge for each of
Table 4 Delay in admission and average total hospitalisation

\begin{tabular}{|c|c|c|c|c|}
\hline $\begin{array}{l}\text { Delay in } \\
\text { admission }\end{array}$ & $\begin{array}{c}\text { Number of } \\
\text { patients }\end{array}$ & $\begin{array}{l}\text { legia } \\
\text { Average } \\
\text { hospital- } \\
\text { isation in } \\
\quad \text { weeks }\end{array}$ & $\begin{array}{c}\text { Number of } \\
\text { patients }\end{array}$ & $\begin{array}{l}\text { legia } \\
\text { Average } \\
\text { hospital- } \\
\text { isation in } \\
\text { weeks }\end{array}$ \\
\hline Group 1 & $67(30.60 \%)$ & 19 & $88(40.2 \%)$ & 22 \\
\hline Group 2 & $25(11.4 \%)$ & 22 & $20(9.1 \%)$ & 25.25 \\
\hline Group 3 & $11(5 \%)$ & 74 & $8(3.7 \%)$ & 41.75 \\
\hline
\end{tabular}

Table 5 Discharge destinations

\begin{tabular}{lcc}
\hline Home & Other hospitals and nursing homes & Deaths \\
\hline 198 & 12 & 9 \\
\hline
\end{tabular}

the patients' groups. To compare the average hospitalisation length between the groups for paraplegic and tetraplegic patients, the Kruskal-Wallis oneway analysis of variance was used. This test reveals that there is evidence that the average hospitalisation of paraplegic patients varies between the three groups $(P<0.001)$. Multiple comparisons between groups suggest that there are differences between groups 1 and 3, and between groups 2 and 3, but not between groups 1 and 2. For the tetraplegic patients the Kruskal-Wallis test again suggests that the average hospitalisation varies across the groups $(P=0.0074)$. Multiple comparisons between groups suggest that the only significant difference is between groups 1 and 3 . The small numbers of patients is probably the reason why the comparison between groups 2 and 3 failed to reach statistical significance. For the multiple comparisons, the test of significance were carried out at the $5 \%$ level and a significance difference implies $P<0.05$ and non-significance that of $P>0.05$.

Regarding secondary complications there were no statistically significant differences in the incidence of most recognised problems for patients in the three groups. There was however, one statistically significant finding (standard error of difference between percentages test). Early admission patients with paraplegia in group 1 were less likely to develop pressure sores compared with group 2, 3 or groups 2 and 3 combined $(0.05>P>0.01,0.05>P>0.01, P>0.01)$. Similarly in the tetraplegic population the earlier admitted group 1 had lower incidence of pressure sores compared with group 3 or groups 2 and 3 combined $(P<0.01$, $P<0.01)$.

Our Centre does not use or advise about the use of high doses of methylprednisolone in the acute stage following injury.

\section{Discussion}

The data in Table 6 lists the different complications encountered among the patients. The complications 
Table 6 Secondary complications of spinal cord injury during initial hospitalisation-comparison of early, delayed and late admissions

\begin{tabular}{|c|c|c|c|c|c|c|c|c|}
\hline \multirow[b]{2}{*}{ Complications } & \multicolumn{4}{|c|}{ Paraplegia } & \multicolumn{4}{|c|}{ Tetraplegia } \\
\hline & $\begin{array}{c}\text { Group } \\
1 \\
\mathrm{n}=67\end{array}$ & $\begin{array}{c}\text { Group } \\
2 \\
\mathrm{n}=25\end{array}$ & $\begin{array}{c}\text { Group } \\
3 \\
\mathrm{n}=11\end{array}$ & $\begin{array}{c}\text { Group } \\
2+3 \\
\mathrm{n}=36\end{array}$ & $\begin{array}{c}\text { Group } \\
1 \\
\mathrm{n}=88\end{array}$ & $\begin{array}{l}\text { Group } \\
2 \\
\mathrm{n}=20\end{array}$ & $\begin{array}{c}\text { Group } \\
3 \\
\mathrm{n}=8\end{array}$ & $\begin{array}{c}\text { Group } \\
2+3 \\
\mathrm{n}=28\end{array}$ \\
\hline $\begin{array}{l}1 \text { Deep Vein } \\
\text { Thrombosis }\end{array}$ & $3(4.5 \%)$ & $1(4 \%)$ & - & $1(2.8 \%)$ & $2(2.3 \%)$ & - & - & - \\
\hline $\begin{array}{l}2 \text { Pulmonary } \\
\text { Embolus }\end{array}$ & - & - & - & - & $1(1.1 \%)$ & - & - & - \\
\hline 3 Pressure Sores & $1(1.5 \%)$ & $5(20 \%)^{*}$ & $3(27.3 \%)^{*}$ & $8(22.2 \%)^{* *}$ & $1(1.1 \%)$ & $1(5 \%)$ & $4(50 \%)^{* *}$ & $5(17.9 \%)^{* *}$ \\
\hline 4 Contracture & - & - & - & - & - & - & $2(25 \%)$ & $2(7.1 \%)$ \\
\hline $\begin{array}{l}5 \text { Heterotopic } \\
\text { Ossification }\end{array}$ & $1(1.5 \%)$ & - & $1(9.1 \%)$ & $1(2.8 \%)$ & $2(2.3 \%)$ & $\begin{array}{c}1(5 \%) \\
-\end{array}$ & - & $1(3.6 \%)$ \\
\hline $\begin{array}{l}6 \text { Broncho- } \\
\text { pneumonia }\end{array}$ & $2(3 \%)$ & - & - & - & $5(5.7 \%)$ & $3(15 \%)$ & - & $3(10.7 \%)$ \\
\hline $\begin{array}{c}7 \text { Respiratory } \\
\text { Failure }\end{array}$ & - & - & - & - & $1(1.1 \%)$ & - & - & - \\
\hline 8 Cardiac Arrest & - & - & - & - & $6(6.8 \%)$ & - & - & - \\
\hline 9 Perforated DU. & - & - & - & - & $1(1.1 \%)$ & - & - & - \\
\hline 10 Epididymoorchitis & $1(1.5 \%)$ & - & - & - & $1(1.1 \%)$ & $1(5 \%)$ & - & $1(3.6 \%)$ \\
\hline 11 Septicaemia & - & $1(4 \%)$ & - & $1(2.8 \%)$ & - & $1(5 \%)$ & - & $1(3.6 \%)$ \\
\hline 12 Bladder Stone & $2(3 \%)$ & $2(8 \%)$ & $2(18.2 \%)$ & $4(11.1 \%)$ & - & $1(5 \%)$ & - & $1(3.6 \%)$ \\
\hline $\begin{array}{l}13 \text { Depression } \\
\text { needing treatment }\end{array}$ & $3(4.5 \%)$ & $2(8 \%)$ & - & $2(5.6 \%)$ & $4(4.6 \%)$ & $1(5 \%)$ & - & $1(3.6 \%)$ \\
\hline 14 Hydronephrosis & - & - & $2(18.2 \%)$ & $2(5.6 \%)$ & - & - & - & - \\
\hline
\end{tabular}

$0.05>P>0.01^{*}, P<0.01^{* *}$

involving the venous system remain a major site of morbidity and mortality in patients with an acute spinal cord injury. The Table indicates a slightly higher risk for development of deep vein thrombosis among early admitted patients than among late admissions despite routine anticoagulation at the Centre. However this was not of statistical significance and we have no information about deep vein thrombosis and death from pulmonary emboli in patients not referred to the Midlands Centre for Spinal Injury.

Cardiac arrest among high tetraplegic patients was a relatively common complication and related to the very old. ${ }^{8,9}$ The number of patients over the age of 60 years was 37 . All patients were closely monitored with comprehensive ITU like supervision. ${ }^{10}$ Atropine was given routinely whenever the heart rate fell below 50 per min. Despite the intervention $6.8 \%$ of tetraplegic patients had a cardiac arrest which indicates the more severely disabled patients being admitted early. ${ }^{11}$ Unfortunately there is no mechanism to find out how many patients died before transfer to the Centre. $^{8}$

There was a statistical significant increase in pressure sores when transfer to the Midland Centre for Spinal Injury was delayed for over a period of 1 week. This is similar to the findings in the University of Michigan study. ${ }^{12}$ The high risk for development of contractures in the 3 rd group $^{6}$ was also identified though not of statistical significance. The musculoskeletal complications can be prevented by early involvement of the rehabilitation professionals during the acute phase of care in specific stretching programmes.

The incidence of heterotopic ossification was small and insufficient for analysis. ${ }^{13}$ We do not know the true percentage of the complication in patients treated outside the Spinal Injury Centre.

Urological complications such as hydronephrosis, bladder stones and epididymo-orchitis occurred at a reduced frequency when patients were admitted early, undoubtedly reflecting advances in urological management and early widespread use of intermittent catheterisation. $^{14}$ None of the patients developed urethral fistula. The importance of regular urological follow up has been reinforced in this population between 1985 and 1988 .

\section{Conclusion}

In conclusion patients admitted early to the specialist Spinal Centre have a significantly lower risk of developing pressure sores. The incidence of other complications related to the multi-system impairment is relatively low considering that no prophylactic antibiotics were given. The true comparative incidence of these complications in patients treated outside the Spinal Injury Centre is unknown. The death rate in patients treated outside the Spinal Injury Centre is also unknown. 


\section{Acknowledgements}

We would like to acknowledge the help and assistance of Dr Mary Jones, Department of Mathematics, University of Keele, Dr Tony Ward and Dr D Shut for their advice and support.

\section{References}

1 Swain A, Grundy D, Russell J. ABC of Spinal Cord Injury. BMJ 1985; 291: 1558 - 1560. 1986; 292: 743 - 745 .

2 Donovan WH et al. Incidence of medical complications in spinal cord injury: patients in specialised, compard with non-specialised centres. Paraplegia 1984; 22: $282-290$.

3 De Vivo MJ, Kartus PL, Stover SL, Fine PR. Benefits of early admission to an organised cord injury care system. Paraplegia 1990; 28: $545-555$.

4 Heinemann AW, Yarkony GM, Roth EJ et al. Functional outcome following spinal cord injury: a comparison of specialised spinal cord injury centre vs general hospital shortterm care. Arch Neurol 1989; 46: $1098-1102$.

5 Yarkony GM, Bass LM, Keenan V, Meyer PR. Contractures complicating spinal cord injury: incidence and comparison between spinal cord centre and general hospital acute care Paraplegia 1985; 23: 265-271.
6 Tator $\mathrm{CH}$ et al. Complications and costs of management of acute spinal cord injury. Paraplegia 1993; 31: 700-704.

7 Gupta A, El Masry WS. Multilevel spinal injuries; incidence, distribution and neurological pattern. J Bone J Surg (Br) 1989; 71-B: $692-695$.

8 De Vivo MJ et al. Cause of death for patients with spinal cord injury. Arch Intern Medicine 1989; 149: 1761-1766.

9 Polatty RC, McElaney MA, Marcelino V. Pulmonary complications in the spinal cord injury patient. Phys Med Rehabil State of Art Rev 1987; 1: 353-373.

10 McMichan JC, Michel L, Westbrook PR. Pulmonary dysfunction following traumatic quadriplegia. JAMA 1980; 243: $528-$ 531.

11 Bellamy R, Pitts FW, Stauffer ES. Respiratory complications in traumatic quadriplegia. J Neurosurg 1973; 39: 596-600.

12 Maynard FM, Weingarden S. Secondary complications of spinal cord injury. Spinal Cord Injury: The Model. Proceedings of the national consensus conference on catastrophic illness and injury. 1990; 57-65.

13 Lal S, Hamilton BB, Heinemann A, Betts HB. Risk factors for heterotropic ossification in spinal cord injury. Arch Phys Med Rehabil 1989; 70: $387-390$.

14 Bedbrook Sir G. (ed). The Care and Management of Spinal Cord Injuries. Spring Valley: USA, 1981. 